\title{
Imatinib-Induced Keratosis Pilaris in a Patient with Chronic Myeloid Leukemia
}

\author{
Maruma $\mathrm{F}^{1^{*}}$ \\ ${ }^{1}$ Consultant, Department Of Dermatology, Universitas Academic Hospital, Bloemfontein, South Africa
}

Corresponding Author: Frans Maruma, MBChB, Dip-Hiv-Med, MMed, AAAM, FC Derm

Address: Department of Dermatology, University Of Free State, Faculty Of Health Sciences, Bloemfontein, South Africa; Email: fransmaruma2@icloud.com,marumaf@ufs.ac.za

Received date: 03 September 2020; Accepted date: 21 September 2020; Published date: 30 September 2020

Citation: Maruma F. Imatinib-Induced Keratosis Pilaris in a Patient with Chronic Myeloid Leukemia. Asp Biomed Clin Case Rep. 2020 Sept 30;3(3):221-24.

Copyright (C) 2020 Maruma F. This is an open-access article distributed under the Creative Commons Attribution License, which permits unrestricted use, distribution, and reproduction in any medium provided the original work is properly cited.

\begin{abstract}
We discuss the case of a 23 years old female with chronic myeloid leukemia. This patient developed keratosis pilaris nearly three months after she was treated with imatinib mesylate for her chronic myeloid leukemia. She was then referred to our dermatology outpatient clinic for assessment of the skin lesions. Prior to initiating the tyrosinase kinase inhibitor, the patient had no skin lesions at all. The skin lesions were widespread and diffuse in distribution and featured a primary morphology of follicular keratotic papules. This clinical picture was in keeping with keratosis pilaris. The further histological evaluation also confirmed features compatible with this diagnosis. The tyrosine kinase inhibitors are considered first-line therapy for the treatment of chronic myeloid leukemia. Imatinib mesylate belongs to the first generation of oral tyrosine kinase inhibitors and has a long-term control on the chronic myeloid leukemia and good safety profile. Most cases of keratosis pilaris are reported to arise from the second generation of tyrosine kinase inhibitors such as Nilotinib. We report a case of keratosis pilaris associated with imatinib mesylate in a patient with chronic myeloid leukemia.
\end{abstract}

\section{Keywords}

Imatinib Mesylate, Keratosis Pilaris, Chronic Myeloid Leukemia,Tyrosine Kinase Inhibitors

\section{Abbreviations \\ CML - Chronic Myeloid Leukemia, TKI - Tyrosine Kinase Inhibitor, KP - Keratosis Pilaris}

\section{Introduction}

Chronic Myeloid Leukemia (CML) is a neoplastic myeloproliferative disorder hall-marked by the dysregulated production and uncontrolled proliferation of both maturing and matured granulocytes however with a fairly normal differentiation. Given the pathophysiology of this disease, targeted therapy for this condition is necessary. The first-line therapy of CML is tyrosine kinase inhibitors (TKI) [1]. Imatinib mesylate is a first-generation oral TKI approved for the treatment of CML and has long-term control over the disease and good safety profile [2]. There is data to suggests that the United States of America would have $>180$,000 patients living with CML by the year 2050 [3]. With an increase of such prevalence, cutaneous adverse effects that are rare may begin to surface. We report a case of imatinib mesylate associated keratosis pilaris in a patient with CML. Several reports in the 
Citation: Maruma F. Imatinib-Induced Keratosis Pilaris in a Patient with Chronic Myeloid Leukemia. Asp Biomed Clin Case Rep. 2020 Sept 30;3(3):221-24.

Case Report

literature have reported $\mathrm{KP}$ almost always in association with second-generation TKI, nilotinib.

\section{Case Report}

A 23 years old female patient with background chronic myeloid leukemia presented to our clinic with an asymptomatic skin rash on her back, outer arms, and legs. She reported that the lesions started 3 months after taking imatinib for chronic myeloid leukemia. Initially, the rash was not severe but became increasingly worse over a period of time.

At the initial presentation, a widespread keratotic follicular papules without perifollicular hemorrhage was evident mostly over the outer aspect of arms, back, and lower extremities. The individual keratotic papules exhibited a pigmented appearance when compared to the surrounding non-lesional skin (Fig1, Fig-2, and Fig-3). There were no features of atopy. Further examination of the integumentary system revealed normal nails with no acral or scalp lesions. The clinical impression was that of keratosis pilaris.

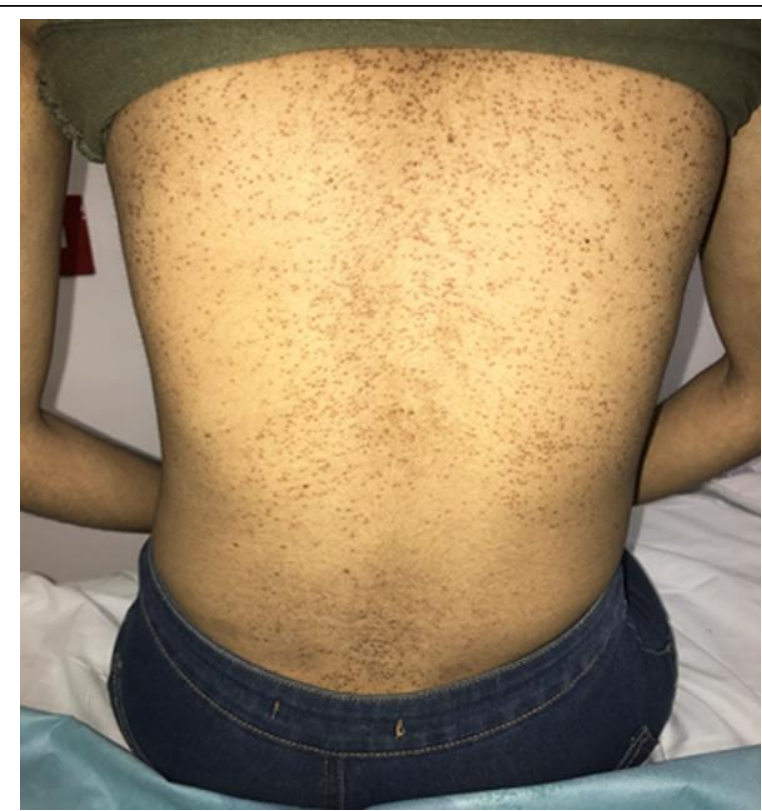

Fig-1: Multiple keratotic follicular papules Involving the back.

A confirmatory skin punch biopsy was performed on a representative lesion over the right upper arm. The histopathological section of this sample demonstrated mild epidermal acanthosis with multiple follicular plugging and no malignant infiltrate to suggest chronic myeloid leukemia. The clinicopathological correlation was consistent with the diagnosis of keratosis pilaris in a patient with a temporal relation of imatinib initiation and the development of skin lesions of the disease.

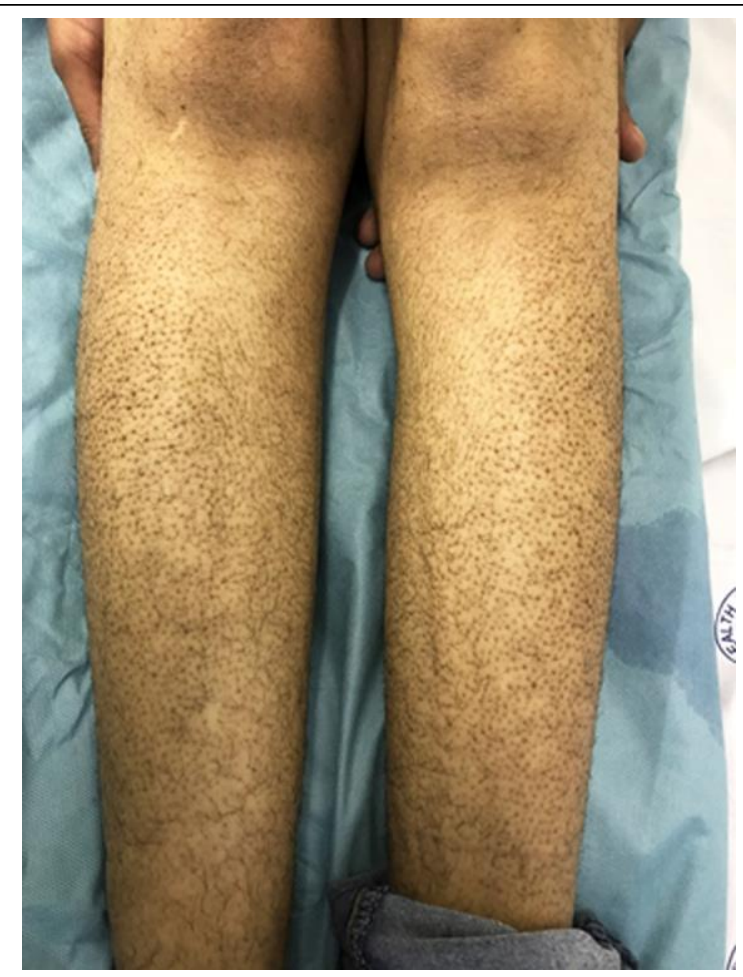

Fig-2: Anterior shins showing diffuse follicular keratotic papules.

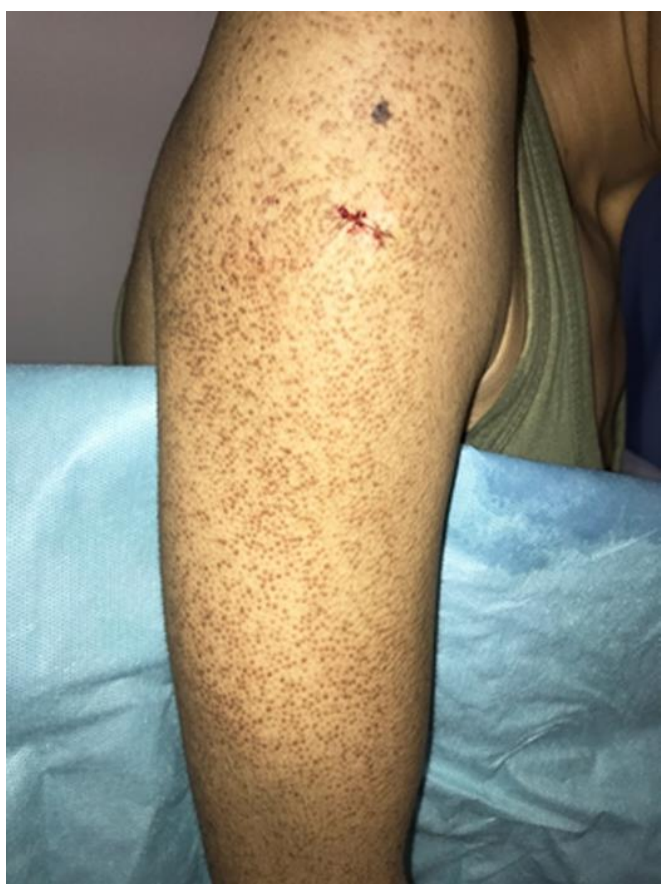

Fig-3: Multiple diffuse and hyperpigmented folliculocentric papules on right upper arm. An area where a skin biopsy was performed. 


\section{Discussion}

This case epitomizes the rare cutaneous adverse effect of imatinib mesylate. Common reported cutaneous adverse effects of imatinib are edema of the face and peripheries, non-specific skin rash, dermatitis, pruritus, night sweats, alopecia, diaphoresis, and pigmentary problems [4-6]. The current consensus is that TKI's are first-line therapy for CML [7]. In this group, imatinib (as the first generation), and second-generation TKI's namely, dasatinib, nilotinib, and bosutinib are all available for use with good efficacy and safety data [8]. There are case reports in literature citing nilotinib as the cause of keratosis pilaris [9,10]. Cutaneous eruptions of TKI's may prove to be a psycho-dermatologic challenge particularly to young and adolescent patients whose self-consciousness and aesthetic appearance mean everything to them and their peers.

Our patient was treated with topical keratolytic and emollients such that a near-complete clearance of the lesions was achieved. We did not use antihistamines, as our patient had no pruritus or dermatitis. It must be noted that the patient was having a psychosocial concern over the skin lesions and through multidisciplinary supportive care and counseling, she was able to accept that Imatinib may not be stopped as the cutaneous reaction was not life-threatening.

In conclusion, this case adds keratosis pilaris to the list of possible cutaneous reactions resulting from Imatinib therapy as a first-generation TKI. Furthermore, clinicians should be aware of the psychosocial disturbances that could accompany the cutaneous adverse reaction of the TKI's.

\section{Acknowledgements and Disclosures}

The author of this publication has not received any financial support and there is no conflict of interest to declare. Informed consent was obtained from the patient and ethical clearance was granted by the University Of Free State's ethics committee.

\section{References}

[1] O'Brien SG, Guilhot F, Larson RA, Gathmann I, Baccarani M, Cervantes F, Cornelissen JJ, Fischer T, Hochhaus A, Hughes T, Lechner K, Nielsen JL,
Rousselot P, Reiffers J, Saglio G, Shepherd J, Simonsson B, Gratwohl A, Goldman JM, Kantarjian H, Taylor K, Verhoef G, Bolton AE, Capdeville R, Druker BJ; IRIS Investigators. Imatinib compared with interferon and low-dose cytarabine for newly diagnosed chronic-phase chronic myeloid leukemia. N Engl J Med. 2003 Mar 13;348(11):994-1004. [PMID: 12637609]

[2] Hochhaus A, Larson RA, Guilhot F, Radich JP, Branford S, Hughes TP, Baccarani M, Deininger MW, Cervantes F, Fujihara S, Ortmann CE, Menssen HD, Kantarjian H, O'Brien SG, Druker BJ; IRIS Investigators. Long-Term Outcomes of Imatinib Treatment for Chronic Myeloid Leukemia. N Engl J Med. 2017 Mar 9;376(10):917-27. [PMID: 28273028]

[3] Huang X, Cortes J, Kantarjian H. Estimations of the increasing prevalence and plateau prevalence of chronic myeloid leukemia in the era of tyrosine kinase inhibitor therapy. Cancer. 2012 Jun 15;118(12):3123-27. [PMID: 22294282]

[4] Cortes J, Quintás-Cardama A, Kantarjian HM. Monitoring molecular response in chronic myeloid leukemia. Cancer. 2011 Mar 15;117(6):1113-22. [PMID: 20960522]

[5] Paolino G, Didona D, Clerico R, Corsetti P, Ambrifi M, Bottoni U, Calvieri S. Skin lesions in patients treated with imatinib mesylate: a 5-year prospective study. Cutis. 2016 Jun;97(6):E12-16. [PMID: 27416091] [6] Scheinfeld N. Imatinib mesylate and dermatology part 2: a review of the cutaneous side effects of imatinib mesylate. J Drugs Dermatol. 2006 Mar;5(3):228-31. [PMID: 16573254]

[7] Iqbal N, Iqbal N. Imatinib: a breakthrough of targeted therapy in cancer. Chemother Res Pract. 2014;2014:357027. [PMID: 24963404]

[8] Hochhaus A, Baccarani M, Silver RT, Schiffer C, Apperley JF, Cervantes F, Clark RE, Cortes JE, Deininger MW, Guilhot F, Hjorth-Hansen H, Hughes TP, Janssen JJWM, Kantarjian HM, Kim DW, Larson RA, Lipton JH, Mahon FX, Mayer J, Nicolini F, Niederwieser D, Pane F, Radich JP, Rea D, Richter J, Rosti G, Rousselot P, Saglio G, Saußele S, Soverini S, Steegmann JL, Turkina A, Zaritskey A, Hehlmann R. European LeukemiaNet 2020 recommendations for treating chronic myeloid leukemia. Leukemia. 2020 Apr;34(4):966-84. [PMID: 32127639]

[9] Leong WM, Aw CW. Nilotinib-Induced Keratosis 

Case Rep. 2020 Sept 30;3(3):221-24.

Pilaris. Case Rep Dermatol. 2016 Apr 21;8(1):91-96.

[PMID: 27194977]

[10] Tawil MH, El Khoury R, Tomb R, Ghosn M. Nilotinib-induced Keratosis Pilaris Associated with Alopecia Areata and Eyebrow Thinning. Int J Trichology. 2017 Apr-Jun;9(2):87-89. [PMID: 28839396] 